\title{
Humic-like acids from hydrochars: Study of the metal complexation properties compared with humic acids from anthropogenic soils using PARAFAC and time- resolved fluorescence
}

João Vitor do Santos ${ }^{\mathrm{a}}$, Lais Gomes Fregolente ${ }^{\mathrm{a}, \mathrm{b}}$, Altair Benedito Moreira ${ }^{\mathrm{a}}$, Odair Pastor Ferreira $^{\mathrm{b}}$, Stéphane Mounier ${ }^{\mathrm{c}}$, Bruno Viguier ${ }^{\mathrm{c}}$, Houssam Hajjoul ${ }^{\mathrm{c}}$, and Márcia Cristina Bisinoti $^{\mathrm{a}^{*}}$

${ }^{\text {a }}$ Laboratório de Estudos em Ciências Ambientais, Departamento de Química e Ciências Ambientais, Instituto de Biociências, Letras e Ciências Exatas, Universidade Estadual Paulista "Júlio de Mesquita Filho," 15054-000, São José do Rio Preto, São Paulo, Brazil.

${ }^{\mathrm{b}}$ Laboratório de Materiais Funcionais Avançados (LaMFA), Departamento de Física, Universidade Federal do Ceará, 60455-900, Fortaleza, Ceará, Brazil.

c Laboratoire MIO-Equipe CEM, Université de Toulon, CS 60584, 83041, CEDEX 9, Toulon, France.

\section{*Corresponding author}

Name: Márcia Cristina Bisinoti

E-mail: marcia.bisinoti@unesp.br

Phone: +55 17 3221-2352

Address: Laboratório de Estudos em Ciências Ambientais, Departamento de Química e Ciências Ambientais, Instituto de Biociências, Letras e Ciências Exatas, Universidade Estadual Paulista “Júlio de Mesquita Filho”, Rua Cristóvão Colombo, 2265, 15054-000, São José do Rio Preto, São Paulo State, Brazil. 


\section{Abstract}

2 Humic acids (HA) play an important role in the distribution, toxicity, and bioavailability

3 of metals in the environment. Humic-like acids (HLA) that simulate geochemical

4 processes can be prepared by $\mathrm{NaOH}$ aqueous extraction from hydrochars produced by

5 hydrothermal carbonization (HTC). HLA can exhibit properties such as those found in

6 HA from soils, which are known for their ability to interact with inorganic and organic

7 compounds. The molecular characteristics of HLA and HA help to explain the

8 relationship between their molecular features and their interaction with metallic species.

9 The aim of this study is to assess the molecular features of HA extracted from Terra

Mulata (TM) and HLA from hydrochars as well as their interaction with metals by using $\mathrm{Cu}$ (II) ions as a model. The results from ${ }^{13} \mathrm{C}$ NMR, elemental analysis, FTIR, and UV-Vis showed that HA are composed mostly of aromatic structures and oxygenated functional groups, whereas HLA showed a mutual contribution of aromatic and aliphatic structures as main constituents. The interactions of HA and HLA with $\mathrm{Cu}$ (II) ions were evaluated through fluorescence quenching, in which the density of complexing sites per gram of carbon for interaction was higher for HLA than for HA. Furthermore, the HLA showed similar values for stability constants, and higher than those found for other types of HA in the literature. In addition, the average lifetime in both humic extracts appeared to be independent of the copper addition, indicating that the main mechanism of interaction was static quenching with a non-fluorescent groundstate complex formation. Therefore, the HLA showed the ability to interact with $\mathrm{Cu}$ (II) ions, which suggests that their application can provide a new approach for remediation of contaminated areas.

Keywords: hydrothermal carbonization, anthropogenic soils, complexation, 


\section{Introduction}

Metal pollution is a worldwide environmental issue in which human activity plays a major role (Lesmana et al., 2009; Li et al., 2014). Unlike most organic contaminants, metals are not biodegradable and can accumulate in living organisms, thereby causing problems for both human health and the environment (Lesmana et al., 2009). Some metals of great concern are cadmium, zinc, copper, and nickel (Li et al., 2014; Tang et al., 2014). Among them, copper is important for cellular metabolism. However, this element is highly toxic if swallowed at high concentrations and can cause gastrointestinal problems, hair loss, weight loss, and even death (Andreazza et al., 2010; Fu and Wang, 2011; Tang et al., 2014). Intensified industrial, agricultural, mining, and urbanization activities are the main causes of copper contamination (Hladun et al., 2015; MacKie et al., 2012). Therefore, research is needed to develop techniques for reducing the concentrations of metals in contaminated soils.

It is widely accepted that soil fertility depends on the presence of nutrients and organic matter (Stevenson, 1994). Humic substances (HS) are the main constituents of soil organic matter and are formed from the remains of plant and animal degradation. Humic acids (HA) are one of the components of HS. They represent the most hydrophobic part and play important roles in soil fertility, water retention, plant growth promotion, and interaction with organic and inorganic compounds (Bento et al., 2019; Canellas and Façanha, 2004; Jindo et al., 2016). The bioavailability, distribution, and toxicity of pollutants are affected by their interaction (He et al., 2016; Tang et al., 2014); thus, the use of HA has gained attention for remediation (Piccolo et al., 2019).

Anthropogenic soils such as TM occur near the Amazon basin and are known for exhibiting high fertility (Glaser et al., 2000; Oliveira et al., 2018). Such soils have gained the attention of researchers who have attempted to reproduce their organic matter 
by thermochemical methods of biomass conversion, such as pyrolysis and hydrothermal carbonization (HTC). These methods use various biomass types to obtain a material with the characteristics of TM.

The HTC process is a suitable biomass disposal method for the production of carbon-based materials known as hydrochar. In addition, the process water (liquid phase) is generated by this method. Some authors have proposed the use of this process water as a hydrothermal medium in a new carbonization process (Kabadayi Catalkopru et al., 2017; Stemann et al., 2013; Weiner et al., 2014) or for liquid fertilizer (Fregolente et al., 2018).

Most HA used in the literature are extracted from soils, water, sediments, or peat (Chen et al., 2015; Plaza et al., 2005; Zherebtsov et al., 2015). The formation of these environmental elements under natural conditions requires significant amounts of time and involves several chemical and biological reactions that can last for years (Yang et al., 2019a). However, the formation of HTC needs only hours (Melo et al., 2017; Silva et al., 2017). Humic-like acids (HLA) are defined as extracts of different organic materials that have not undergone the natural process of humification (Bento et al., 2019; Jindo et al., 2016, 2019). Although there is not the natural humification process that occurs in soils, HLA extracted from hydrochars might have characteristics similar to those of natural HA extracted from anthropogenic soils, which are known as a model of organic matter. Knowledge of the chemical structure of HLA is essential for predicting their behavior and benefits in soil.

Because natural HA form complexes with metals (Stevenson, 1994), the study of interaction between metallic ions and HLA is of significant value for predicting whether HLA can assist in the complexation reactions if applied to the soil, and thus the metal bioavailability. A variety of agents has been used for soil washing including 
biosurfactants as well as synthetic agents such as ethylenediaminetetraacetic acid (EDTA) (Mulligan et al., 2001, Mulligan, 2009). Despite the efficiency of these agents in removing metals from soils, they cause environmental problems and are high in cost, which justifies the need for more studies to develop new washing agents. In previous research, a solution of HLA from manure compost biochar showed the remediation of soils contaminated by multiple metals (Kulikowska et al., 2015); the same was shown for HLA from composted sewage sludge (Piccolo et al., 2019). In addition, the potential of HLA extracted from hydrochars produced with crude waste biomass was presented (Yang et al., 2019a). In that case, HLA from hydrochars produced with by-products of the sugarcane industry were shown to act in complexation reactions between metals and active sites on the HLA surface.

The fluorescence excitation emission matrix (EEM) has gained prominence in the characterization of organic matter and its interaction with metallic species (Elkins and Nelson, 2002). The analytical potential of fluorescence EEM spectra coupled with chemometric tools such as Parallel Factor Analysis (PARAFAC) has been successfully realized for this type of analysis (Mounier et al., 2011; Nouhi et al., 2018; Stedmon and Bro, 2008; Tadini et al., 2019; Yuan et al., 2015). Moreover, PARAFAC has also been used in the characterization of dissolved organic matter (DOM) of biochars produced with different biomass content (El-Naggar et al., 2020; Rajapaksha et al., 2019; Yang et al., 2019b). Further, because different chemical species have different fluorescence lifetimes, it is also possible to study organic matter-metal interaction through timeresolved fluorescence (TRF), particularly in complex samples such as HA and HLA (Nouhi et al., 2018).

Thus, the chemical characterization of HLA from hydrochars obtained with sugarcane industry by-products was conducted, and the results were compared with that 
of HA from TM. In addition, the interaction of HA and HLA with $\mathrm{Cu}(\mathrm{II})$ ions by fluorescence quenching was studied to provide quantitative data on the complexation capacity (CC), concentration of binding sites (CL), and conditional stability constant (K). TRF as a complementary technique of fluorescence quenching was used to investigate the interaction by measuring the fluorescence lifetime and its variation with the addition of metal. Thus, the present study can provide a new perspective for analyzing $\mathrm{Cu}(\mathrm{II})-\mathrm{HLA}$ interactions and the potential of HLA as a complexing agent in the remediation of soils polluted by metals.

\section{Materials and methods}

\subsection{Terra Mulata sampling}

Soil sampling was performed following the 2000 United States Environmental Protection Agency (EPA) method (US EPA, 2000). For this study, three different areas of TM were selected. The first TM soil was obtained from an open area region containing native vegetation and low vegetation cover (TM I; $3^{\circ} 04^{\prime} 05.45^{\prime \prime} \mathrm{S}$ and $\left.58^{\circ} 33^{\prime} 51.11^{\prime \prime} \mathrm{W}\right)$; the second was taken from a closed area region containing native vegetation (TM II; $3^{\circ} 04^{\prime} 05.17^{\prime \prime} \mathrm{S}$ and $58^{\circ} 34^{\prime} 11.68^{\prime \prime} \mathrm{W}$ ); and the third was collected near cultivated areas (TM III; $3^{\circ} 03^{\prime} 59.15^{\prime \prime} \mathrm{S}$ and $58^{\circ} 27^{\prime} 04.64^{\prime \prime} \mathrm{W}$ ). All areas are located near Itacoatiara city in the Amazonas State (Brazil). (SISBio collection was authorized by the Chico Mendes Institute for Biodiversity Conservation, $n{ }^{\circ} 50042-2$, and registered in the National System for the Management of Genetic Heritage and Associated Traditional Knowledge (SisGen), No. A0018C2.) Soil samples were collected from the 0 to $30 \mathrm{~cm}$ deep layer, air-dried, and subsequently sieved through a $2 \mathrm{~mm}$ mesh for removal of plant debris and fragments. 


\subsection{Hydrothermal carbonization and recarbonization process}

HTC was performed using vinasse and sugarcane bagasse, in which the vinasse was used to produce the hydrothermal medium (Melo et al., 2017; Silva et al., 2017). The HTC processes were conducted in a Teflon ${ }^{\circledR}$ closed reactor coated with stainless steel. Each mixture (Table 1) was heated in a muffle furnace at $230{ }^{\circ} \mathrm{C}$ for $13 \mathrm{~h}$. Then, the reactor was cooled in an ice bath, and the suspension was filtered under vacuum filtration to separate the hydrochar from the process water. The hydrochar was washed with distilled water until constant $\mathrm{pH}$ was reached and was then dried at $50{ }^{\circ} \mathrm{C}$ until constant mass was achieved. The process water generated in the HTC process was used in the recarbonization process to produce the hydrothermal medium for sugarcane bagasse carbonization. The subsequent steps after carbonization, i.e., filtration, hydrochar washing, and drying, were the same.

\section{Table 1}

\subsection{Extraction of humic acids and humic-like acids}

The extractions were performed following the recommendations of the International Humic Substances Society (IHSS) (Swift, 1996). HS were extracted from $\mathrm{TM}$ at a proportion of 1:10 (soil:extractor). Thus, the extraction was conducted in $100 \mathrm{~g}$ of soil to $1 \mathrm{~L}$ of solution $\left(\mathrm{NaOH} 0.1 \mathrm{~mol} \mathrm{~L}^{-1}\right)$ under nitrogen flow for $4 \mathrm{~h}$. The solution extracted was acidified with $\mathrm{HCl}\left(6 \mathrm{~mol} \mathrm{~L}^{-1}\right)$ to reach $\mathrm{pH} \sim 1$. Thus, $\mathrm{HA}$ were precipitated, and fulvic acids remained in the supernatant. Subsequently, the HA were separated by centrifugation, dialyzed using a Fisherbrand apparatus with a molecular weight cut-off at 6,000-8,000 Da, and freeze-dried.

The method was modified for the extraction of humic-like substances (Jindo et al., 2016). Those from hydrochars were extracted at a proportion of 1:10 (hydrochar:extractor) using $\mathrm{NaOH}\left(0.1 \mathrm{~mol} \mathrm{~L}^{-1}\right)$ under nitrogen flow for $4 \mathrm{~h}$. This 
151 procedure was repeated, with the same hydrochar portion until the final extract 152 (supernatant phase) showed a lighter color. HLA were obtained by the $\mathrm{pH}$ difference, 153 with $\mathrm{HCl}\left(6 \mathrm{~mol} \mathrm{~L}^{-1}\right)$ to $\mathrm{pH} 1$, and was separated from the fulvic-like acids by 154 centrifugation. Finally, the extracts of HLA obtained from each extraction step were 155 combined, dialyzed, and freeze-dried.

\subsection{Characterization of humic acids and humic-like acids}

158

\subsubsection{Elemental analysis}

Elemental analyses were performed on solids using an elemental analyzer (2400 Series II CHNS/O, Perkin Elmer, Walther, Massachusetts, USA). The oxygen content was determined according to the difference, i.e., $\mathrm{O} \%=100-(\mathrm{C}, \mathrm{H}, \mathrm{N}, \mathrm{S}+$ ashes $)$. The ash content was determined in a muffle furnace at $750{ }^{\circ} \mathrm{C}$ for $4 \mathrm{~h}$. The $\mathrm{C}, \mathrm{H}, \mathrm{N}, \mathrm{S}$, and $\mathrm{O}$ contents were recalculated on an ash-free basis. The $\mathrm{H} / \mathrm{C}, \mathrm{O} / \mathrm{C}$, and $\mathrm{C} / \mathrm{N}$ atomic ratios were determined by elemental analysis (Giovanela et al., 2010; Stevenson, 1994).

\subsubsection{Infrared spectroscopy}

Infrared spectra were obtained using an attenuated total reflectance (ATR)coupled spectrophotometer (FTIR; Spectrum Two UATR, Perkin Elmer, Walther, Massachusetts, USA). The solid material was placed directly on the ATR crystal and was analyzed at a spectral range of $4000-400 \mathrm{~cm}^{-1}$ with 20 scans and a resolution of 4 $\mathrm{cm}^{-1}$.

\subsubsection{Ultraviolet-visible spectroscopy}

The ultraviolet-visible (UV-Vis) scanning spectra were obtained by employing a UV-Vis spectrophotometer (UV-2600, Shimadzu, Japan) at a range of 200-700 nm. HA 
and HLA solutions (10 $\mathrm{mg} \mathrm{L}^{-1}$ ) in total organic carbon (TOC; TOC-VCSN Shimadzu, Japan) were diluted in $0.05 \mathrm{~mol} \mathrm{~L}^{-1}$ of $\mathrm{NaHCO}_{3}$ at $\mathrm{pH}$ 8. From the spectra, the ratios $\mathrm{E}_{465} / \mathrm{E}_{665}(\mathrm{E} 4 / \mathrm{E} 6)$ and $\mathrm{E}_{270} / \mathrm{E}_{407}(\mathrm{E} 2 / \mathrm{E} 4)$ were calculated. These ratios have been used to describe the degree of aromatic ring condensation and the presence of lignin derivatives, respectively (Budziak et al., 2004; Canellas and Façanha, 2004).

\subsubsection{Solid-state ${ }^{13} \mathrm{C}-\mathrm{CPMAS}-\mathrm{NMR}$ spectroscopy}

Solid-state ${ }^{13} \mathrm{C}$-cross-polarized magic angle spinning (CPMAS)-nuclear magnetic resonance (NMR) characterization was performed by employing a Bruker AVANCE $400 \mathrm{MHz}$ spectrometer (Bruker, Billerica, Massachusetts, USA) equipped with a magic angle spin (MAS) probe. A zircon cylindrical rotor with a diameter of 4.0 mm was packed with $80 \mathrm{mg}$ of sample. The spectra were acquired by using a rotor rotation frequency of $10 \mathrm{kHz}$, recycle time of $1 \mathrm{~s}$, and 5,000 scans. The spectral areas were integrated and divided into seven chemical shifts: C-alkyl (0-45 ppm), Cmethoxyl (45-60 ppm), O-alkyl-C (60-110 ppm), aryl-C (110-145 ppm), phenol-C (145-160 ppm), carboxyl-C (160-190 ppm), and carbonyl-C (190-220 ppm). According to the area integration, the aromaticity (ARM), alkyl (A/AO), and hydrophobicity (HB/HI) indices were calculated. (Monda et al., 2018).

\subsection{Interaction of humic acids and humic-like acids with $\mathrm{Cu}$ (II)}

\subsubsection{Fluorescence quenching}

Studies involving interaction with $\mathrm{Cu}(\mathrm{II})$ ions were performed using $10 \mathrm{mg} \mathrm{L}^{-1}$ of HA or HLA in a buffer medium with $0.1 \mathrm{~mol} \mathrm{~L}^{-1}$ 4-(2-hydroxyethyl)-1piperazineethanesulfonic acid (HEPES) at $\mathrm{pH}$ 7.0. Titration experiments were performed in 13 cuvettes for each HA or HLA sample with various concentrations of 
$201 \mathrm{Cu}(\mathrm{II})\left(\mathrm{Cu}\left(\mathrm{ClO}_{4}\right)_{2} \cdot 6 \mathrm{H}_{2} \mathrm{O}\right)$, ranging from $0 \mathrm{mg} \mathrm{L}^{-1}$ to $11.2 \mathrm{mg} \mathrm{L}^{-1}$. The equilibrium time 202 of 30 min was determined on the basis of changes observed in the fluorescence signal.

203 Fluorescence measurements were performed using a spectrofluorometer (F4500,

204 Hitachi, Santa Clara, California, USA) equipped with a $450 \mathrm{~W}$ xenon lamp. The spectra 205 were acquired in the scan ranges of 220-700 $\mathrm{nm}$ for emission and $220-500 \mathrm{~nm}$ for 206 excitation, with both slits fixed at $5 \mathrm{~nm}$. The scan speed was set at 2,400 $\mathrm{nm} \mathrm{min}{ }^{-1}$, and 207 the detector voltage was $700 \mathrm{~V}$. The obtained EEM spectra were treated by using the PARAFAC chemometric model. The number of components responsible for (Mounier et al., 2011). The density of binding sites (CL) as well as the conditional stability constant $(\mathrm{K})$ were determined following the metal complexation model proposed by Ryan and Weber (1982), as represented by

where $L$ is a free complexing site, $M$ is the free or uncomplexed metal, and $M L$ is the complex. Based on this reaction, the conditional stability constant can be calculated as $K=[M L] /[M][L]$.

Metal and complexing sites follow a mass balance in solution:

$C L=[M L]+[L]$,

$C M=[M L]+[M]$,

where $C L$ and $C M$ represent the total concentration of complexing sites and the metal in the solution system, respectively.

\subsubsection{Time-resolved fluorescence}

Three samples were selected from the data obtained from the fluorescence quenching experiment, i.e., three total copper concentrations for each HA and HLA 
interaction. The first contained no concentration of copper $\left(\mathrm{C}_{0}\right)$, whereas $\mathrm{C}_{0.7}$ and $\mathrm{C}_{5.6}$

227 contained $0.7 \mathrm{mg} \mathrm{L}^{-1}$ and $5.6 \mathrm{mg} \mathrm{L}^{-1}$, respectively. Prior to each measurement, the prepared solution was bubbled with nitrogen for 10 min to prevent photodegradation. TRF experiments were performed at $266 \mathrm{~nm}$ from the fourth harmonic generation from a nanosecond laser Nd:YAG (Quanta-Ray INDI, Spectra Physic, Germany), and excitation $(1024 \mathrm{~nm})$ occurred with a pulse width of $5 \mathrm{~ns}$ and a repetition of $20 \mathrm{~Hz}$. Six hundred spectra were accumulated at each time step of $0.2 \mathrm{~ns}$ with an optical fiber and were detected by an intensified charge-coupled device (CCD) camera with a 35 ns gate associated lifetime values.

\section{Results and discussion}

\subsection{Characterization of humic acids and humic-like acids}

Determining the molecular formula of HA and HLA is still a challenge; however, elemental analysis can provide a general idea about their compositions. The elemental analysis and UV-Vis ratios of soil HA and hydrochar HLA samples are shown in Table 2. In general, HA and HLA showed carbon as the main constituent, at $36.6 \%$ to $62.2 \%$, followed by oxygen, hydrogen, nitrogen, and sulfur. In addition, HLA $\mathrm{RHH}_{2} \mathrm{SO}_{4}$ had the highest sulfur content of the samples. Regarding the carbon percentage, the HLA samples showed higher values than did HA.

The $\mathrm{O} / \mathrm{C}, \mathrm{H} / \mathrm{C}$, and $\mathrm{C} / \mathrm{N}$ atomic ratios (Table 2) based on elemental analysis, have been used to describe the content of oxygenated groups in the molecules, the degree of aromatic ring condensation, and the nitrogen content, respectively (Giovanela et al., 2010; Stevenson, 1994). In general, HA showed higher O/C ratios than those of 
HLA, suggesting a greater abundance of oxygen-containing functional groups (Fukushima et al., 2014). The H/C ratio showed that HA, except for the TM II HA, have higher condensation of aromatic rings than do HLA; lower $\mathrm{C} / \mathrm{N}$ atomic ratios for HA suggest more nitrogen-containing structures (F. Yang et al., 2019).

The UV-Vis spectra of HA have been previously described in the literature and provide little structural information. Generally, however, the overall absorbance decreases with increasing wavelength (Uyguner and Bekbolet, 2005). In this study, both HA and HLA showed this behavior; the spectra are shown in the supplementary material (Figure S1). For better interpretation of UV-Vis analysis, the absorbance ratios at certain wavelengths were utilized. The $\mathrm{E}_{465} / \mathrm{E}_{665}$ absorbance ratio is related to the degree of condensation of aromatic rings. Values lower than 4 indicate compounds with more condensed aromatic groups (Canellas and Façanha, 2004; Stevenson, 1994; He et al., 2016). The $\mathrm{E}_{270} / \mathrm{E}_{407}$ absorbance ratio refers to the presence of lignin derivatives, of which the content is directly proportional to this value (Budziak et al., 2004). This ratio might be indicative for organic matter studies because lignin is involved in the formation of both soils and hydrochars. The obtained parameters are presented in Table 2.

HA showed a higher degree of aromatic condensation than HLA. Furthermore, the lower number of compounds with lignin structures might be linked to greater decomposition of organic matter.

Table 2

The FTIR spectra (Figure 1a and 1b) showed that both HA and HLA have typical features of HS (Esteves et al., 2009; Fernandes et al., 2010; Giovanela et al., 2010). In the $3500-3300 \mathrm{~cm}^{-1}$ region, larger bands were observed for HA. However, the bands for HLA were more defined and might be related to N-H stretching of amines or 
amides and O-H stretching of alcohols and phenols (Dick et al., 2003). The same result was observed for the $\mathrm{C}-\mathrm{H}$ stretching of aliphatic methyl and methylene groups near $2900 \mathrm{~cm}^{-1}$. In the $1730-1710 \mathrm{~cm}^{-1}$ region, low intensity of $\mathrm{C}=\mathrm{O}$ stretching of carboxylic acids or ketones was found for HA (Figure 1a), and a slight shoulder was observed for the HLA samples (Figure 1b) (Senesi et al., 2003). Bands in the $1620-1600 \mathrm{~cm}^{-1}$ regions were associated with aromatic $\mathrm{C}=\mathrm{C}$ stretching (Stevenson, 1994). C-H bending of $\mathrm{CH}_{3}$ and deformation of $\mathrm{CH}_{2}$ and $\mathrm{CH}_{3}$ structures were observed in the $1420-1380 \mathrm{~cm}^{-}$ ${ }^{1}$ region for HLA but not for HA. All spectra showed C-O-C stretching at approximately 1250-1030 $\mathrm{cm}^{-1}$, likely resulting from polysaccharides; stretching in esters, alcohols, and phenols was also observed. In addition, $\mathrm{Si}-\mathrm{O}$ stretching bands were identified in the $825-750 \mathrm{~cm}^{-1}$ region (Giovanela et al., 2010; Stevenson, 1994).

\section{Figure 1}

The ${ }^{13} \mathrm{C}-\mathrm{CPMAS}-\mathrm{NMR}$ spectra of HA and HLA are shown in Figure 2. Both samples showed complex chemical compositions, with peaks related to aromatic and aliphatic carbons, substituted or not by heteroatoms, and different intensities. The following peaks were observed in all samples: $0-45 \mathrm{ppm}$, attributed to the presence of alkyl carbons of methyl and methylene groups; 45-60 ppm for carbons linked to methoxyl groups and nitrogen compounds $(\mathrm{C}-\mathrm{N}) ; 60-110 \mathrm{ppm}$, indicating the presence of oxygen-substituted carbons and alkyl groups (O-alkyl); 110-145 ppm, attributed to the presence of aromatic groups; and 145-160 ppm for substituted aromatic carbons, 160-190 ppm for carbonyl groups, and 190-220 ppm for carboxylic groups in the structures of HA and HLA (Mazzei and Piccolo, 2012; Monda et al., 2017; Spaccini and Piccolo, 2009; Tadini et al., 2015).

Chemical shifts near $15 \mathrm{ppm}$ were assigned to short-chain aliphatic structures, whereas those at $30 \mathrm{ppm}$ were assigned to long-chain aliphatic structures attributed to 
lipid compounds, such as plant waxes and biopolyesters (Francioso et al., 2002; Monda et al., 2017; Spaccini et al., 2019). These peaks were more intense in the HLA samples (Figure 2). The peak at $54 \mathrm{ppm}$, related to the presence of methoxyl carbons in both guaiacil and syringyl units of lignin fragments, as well as $\mathrm{C} \alpha$ of oligo- and polypeptides (Monda et al., 2017), was present for both HA and HLA except in those in which sulfuric acid was used as an additive (Figure 2).

The peaks in the 71-74 ppm range were more evident in HA and are typical of O-akyl-C in mono and polysaccharides, in which the centered peak at $72 \mathrm{ppm}$ is attributed to the overlapping of carbon numbers 2,3 , and 5 in the pyranosidic cellulose and hemicellulose structures, referred to as C-2, C-3, and C-5, respectively (Monda et al., 2017; Spaccini and Piccolo, 2009). Unsubstituted aromatic carbons were responsible for the intense signal at $130 \mathrm{ppm}$ (Monda et al., 2017) in the HA and HLA structures, whereas their analogs containing $-\mathrm{OH},-\mathrm{OCH}_{3}$, and $-\mathrm{NH}_{2}$ groups were found in the 145$160 \mathrm{ppm}$ region. The signal at $174 \mathrm{ppm}$ corresponds to carboxylic acids, and the low signal at 190-220 ppm refers to carbonyl groups of ketones, amides, and aldehyde (Mao et al., 2011) in the HA and HLA, as shown in Figure 2.

\section{Figure 2}

By employing spectral integration, it is possible to estimate the distribution of carbons in the HA and HLA structures as well as some indices such as A/AO, ARM, and HB/HI, as shown in Table 3. These indices are related to the biochemical stability of different organic compounds. The HA showed aromatic compounds as the main constituents, whereas HLA showed the presence of aromatic and aliphatic carbons (Table 3). The ARM index was similar for both materials. Higher HB/HI index values indicate the incorporation of hydrophobic moieties in HLA (Bento et al., 2019). Furthermore, the natural HA were more hydrophilic than those HLA obtained from 
HTC, which is indicated by the decrease in the A/OA index (Table 3). All of these factors, such as presence or absence, greater incorporation of functional groups or not in humic and humic-like acids, influence the binding properties with metal ions.

Table 3

\subsection{Interaction of humic acids and humic-like acids with $\mathrm{Cu}(\mathrm{II})$}

\subsubsection{Fluorescence quenching}

The interactions of $\mathrm{HA}$ and HLA with $\mathrm{Cu}$ (II) ions were evaluated by fluorescence quenching; the concentration of each humic extract was $10 \mathrm{mg} \mathrm{L}^{-1}$. Other authors have used this concentration value of humic extract in experiments for the same purpose: to avoid inner filters (Guo et al., 2015; Yuan et al., 2015). The quenching results were combined with the PARAFAC multivariate statistical tool, in which the complex signal of the fluorescence spectra was decomposed into simple and independent components.

Thus, a three-component model was found for HA quenching experiments with a good CORCONDIA value $(94.75 \%)$. The components are shown in Figure 3. Component 1 (Figure 3a) had a main peak at $\left[\lambda_{\mathrm{Ex}} 300 \mathrm{~nm} / \lambda_{\mathrm{Em}} 475 \mathrm{~nm}\right]$, which is typical of humic-like substances. Component 2 (Figure $3 b$ ) had a secondary peak at $\left[\lambda_{\text {Ex }} 275\right.$ $\mathrm{nm} / \lambda_{\mathrm{Em}} 530 \mathrm{~nm}$ ], which is associated with low-energy peaks known to be typically linked to terrestrial HA (Matthews et al., 1996; Stedmon et al., 2003), and a main peak at $\left[\lambda_{\operatorname{Ex}} 475 \mathrm{~nm} / \lambda_{\mathrm{Em}} 530 \mathrm{~nm}\right]$, which is typical of lignin-derived terrestrial HA. In addition, component 1 showed a blue shift for fluorescence emission intensity, whereas component 2 demonstrated a red shift, characterizing the presence of simple and complex structures, respectively (Senesi et al., 2003). Conversely, component 3 (Figure 3c) showed no variation in its contribution during the quenching experiments, which is 
likely related to a noise factor. Therefore, this component was not considered in the discussion.

A three-component model was also found for the interaction with HLA, with a CORCONDIA value of $97.46 \%$; these components are also shown in Figure 3. Component 1 (Figure 3d) showed a main and a secondary peak at $\left[\lambda_{\mathrm{Ex}} 260 \mathrm{~nm} / \lambda_{\mathrm{Em}} 425\right.$ $\mathrm{nm}]$ and $\left[\lambda_{\mathrm{Ex}} 340 \mathrm{~nm} / \lambda_{\mathrm{Em}} 425 \mathrm{~nm}\right.$ ], respectively. Both components are characteristic of humic substances from terrestrial environments (Coble, 1996; Matthews et al., 1996; Stedmon et al., 2003). Component 2 (Figure 3e) had a main peak at $\left[\lambda_{\mathrm{Ex}} 275 \mathrm{~nm} / \lambda_{\mathrm{Em}}\right.$ $510 \mathrm{~nm}]$ and a secondary peak at $\left[\lambda_{\mathrm{Ex}} 400 \mathrm{~nm} / \lambda_{\mathrm{Em}} 510 \mathrm{~nm}\right]$. The main peak was classified as typically humic-like, and the secondary peak refers to soil fulvic acid. Component 3 (Figure 3f) showed no fluorescence variation; therefore, similar to that for HA, it was not considered in the discussion.

\section{Figure 3}

It is possible to obtain the fluorescence contribution of each component in the sample, known as the score, depending on the metal addition. The initial humic extracts were considered as $100 \%$, and the contribution decreased with the addition of metal. Figure $4 \mathrm{a}$ shows the scores of components 1 and 2 regarding the interaction of TM I HA with $\mathrm{Cu}$ (II) ions, and Figure $4 \mathrm{~b}$ shows those regarding the interaction of $\mathrm{HH}_{2} \mathrm{SO}_{4} \mathrm{HLA}$. All three HA samples showed similar behavior; additional graphs are given in the supplementary material (Figure S2). The four HLA samples also showed similarly behavior, as shown in the supplementary material (Figure S3).

\section{Figure 4}

The fluorescence quenching curve for the first component of $\mathrm{HA}$ and $\mathrm{Cu}(\mathrm{II})$ (Figure 4a) showed a fluorescence intensity decay of approximately $85.6 \%$, and the second component had a value of $92.5 \%$. This significant decay in fluorescence 
contribution is attributed to the formation of a complex in which the fluorescence quantum yield changed (Mounier et al., 2011; Tadini et al., 2019). Moreover, the interaction with $\mathrm{Cu}(\mathrm{II})$ was shown to influence the optical properties of organic matter. For the interaction between HLA and Cu(II) (Figure 4b), the fluorescence intensity decay for the first component remained at approximately $67.3 \%$, whereas that for the second was approximately $58.2 \%$. The decrease in fluorescence intensity of the HA components appeared at the first concentrations of $\mathrm{Cu}$ (II). For the HLA components, an increase in copper concentration was necessary for better visualization of the quenching phenomenon.

Optimization of the data using the 1:1 (ligand:metal) complexation model proposed by Ryan and Weber (1982) enables evaluation of the equilibrium parameters, particularly $\mathrm{CL}$ and $\mathrm{K}$, of which $\mathrm{CL}$ is the concentration of binding sites capable of forming a complex and $\mathrm{K}$ is the conditional stability constant of the complex formed.

The equilibrium parameters for the HA and HLA experiments, including CL, log $\mathrm{K}, \mathrm{CC}$, and the bias values, are given in Table 4. To evaluate the 1:1 complexation model, bias was used as an optimization parameter. Bias is the sum of the absolute value of the difference between the experimental and calculated fluorescence logarithm intensity. In this study, the bias values ranged from 0.27 to 4.18 , which are lower than those found in the literature (Tadini et al., 2019). Therefore, the experimental data fit well in the theoretical model (Table 4). The titration curves of the theoretical and experimental values for components 1 and 2 of HA and components 1 and 2 of HLA with $\mathrm{Cu}(\mathrm{II})$ can be found in the supplementary material (Figures S4 and S5).

\section{Table 4}

For HA components 1 and 2, the $\log \mathrm{K}$ values remained in the ranges of 5.305.41 and 5.58-5.60, respectively; for HLA components 1 and 2, these values were in the 
ranges of 4.88-4.90 and 5.06-5.09, respectively. The HA components showed higher values for $\log \mathrm{K}$ and both blue and red shifts in the fluorescence emission wavelengths. In addition, the fluorophores exhibited different chemical structures and compounds with good binding capacities, which is confirmed by Figure 3a, b. The HLA components showed similar values for $\log \mathrm{K}$ compared with $\mathrm{HA}$ and values either similar to or higher than those found in the literature for other types of HA (Fuentes et al., 2013; Plaza et al., 2005; Tadini et al., 2019). Blue and red shifts were also observed (Figure 3d, e); therefore, the fluorophores have different chemical structures and are weakly bonded compared to HA.

It is noteworthy that TM, which occurs in the Amazon, is different from common soils and has high fertility because of the carbon stock and long-term nutrients. This fact was demonstrated by good interaction with the metal ion (log K 5.30-5.60). HLA showed higher $\log \mathrm{K}$ values than those found in Spodosols, which also occur in the Amazon region (log K 3.79-5.32) (Tadini et al., 2019), or peat and leonardite (log K 4.58-5.10) (Fuentes et al., 2013). This indicates that the organic matter extracted from hydrochars can also interact satisfactorily with $\mathrm{Cu}(\mathrm{II})$ ions to form complexes. Additionally, by using the CL values, it was also possible to determine the $\mathrm{CC}$ for all components 1 and 2 from HA and HLA. This parameter was obtained by dividing the CL values by the carbon content. CC represents the concentration of binding sites per gram of carbon available to interact with $\mathrm{Cu}$ (II) ions. Table 4 also shows the $\mathrm{CC}$ values for HA and HLA components 1 and 2.

Both HLA components 1 and 2 showed higher concentrations of binding sites per gram of carbon for interaction with $\mathrm{Cu}$ (II) ions than those of HA; and the highest value was observed for $\mathrm{RHH}_{2} \mathrm{SO}_{4} \mathrm{HLA}$. Regarding $\log \mathrm{K}$, the $\mathrm{CC}$ values were also higher than those found in the literature for HA from soils, peat, or leonardite (Fuentes 
et al., 2013; Plaza et al., 2005; Tadini et al., 2019). Tadini et al. (2019) determined the

$427 \mathrm{CC}$ of components by fluorescence quenching for HA extracted from Amazonian Spodosols with $\mathrm{Cu}(\mathrm{II})$ ions and found $\mathrm{CC}$ values ranging from $0.01-0.13 \mathrm{mmol}$ of $\mathrm{Cu} \mathrm{g}^{-}$

${ }^{1} \mathrm{C}$. The values found in this study for HA extracted from TM were higher, indicating both a larger amount of complexing sites and an affinity of organic matter with the metallic ion. The same result was observed for HLA, indicating that if applied to the soil, it could help in the complexation reactions.

Previous research indicates that the high stability constants of HA are associated with increased oxygen-containing groups such as $-\mathrm{COOH}$ and $-\mathrm{OH}$ as well as $\pi$ - $\pi$ bonds in the $\mathrm{C}=\mathrm{C}$ of aromatic rings (Guo et al., 2012, 2015). These functional groups were observed for HA and HLA by using both FTIR and ${ }^{13} \mathrm{C}$ NMR techniques. The results show that the predominance of conjugate and aromatic structures as well as oxygencontaining groups are responsible for HA complexation, and for HLA, both aromatic and aliphatic groups are responsible. Pearson established the concept of chemical bonding regarding the affinity of different metals to different ligands (Pearson, 1963). It was reported that chemical species can be classified as "hard" and "soft" or "borderline" acids and bases and that the concepts of "hardness" and "softness" can help to interpret the mechanism of complexation. Soft acids tend to have preferential interaction by soft bases, whereas hard acids tend to bind with hard bases; borderline acids form considerably stable bonds with both hard and soft bases, although it is sometimes explain the stability of chemical compounds (Pearson, 1963). As observed in the ${ }^{13} \mathrm{C}$ NMR spectra and in the $\mathrm{H} / \mathrm{C}, \mathrm{O} / \mathrm{C}$, and $\mathrm{C} / \mathrm{N}$ atomic ratios, HA and HLA showed similar ARM, although HA showed a higher percentage of 
borderline acid and interacts with both hard bases such as oxygen and soft bases such as nitrogen; thus, HA had a stronger interaction with $\mathrm{Cu}(\mathrm{II})$ because of their molecular structures. Lu and Allen (2002) found that the interaction of DOM with $\mathrm{Cu}(\mathrm{II})$ ions is attributed mostly to phenol OH groups, and Hernández (2006) showed a positive and significant correlation with carboxylic acid and phenols. Moreover, the presence of large amounts of functional groups and $\pi-\pi$ bonds of aromatic rings should confer a greater complexation capacity for HA from TM; however, this did not occur potentially owing to the different molecular arrangements. Further, it is possible that the functional groups and aromatic carbons in HA structures were already occupied by another metal or more condensed aromatic rings. All of these factors can affect the behavior of $\mathrm{Cu}$ (II) ions in both soils and hydrochar extracts. Conversely, HLA showed more binding sites available for interaction considering the amount of carbon in the sample, and thus greater complexation capacity. the lifetime of the excited state, affecting the fluorescence lifetime. The second is static quenching, which occurs when a ground-state non-fluorescent complex is formed, and the lifetimes of the fluorescent ligand and complex are unaffected (Lakowics, 1999). HLA complexes with copper, respectively. The deconvolution of TRF results in the HA 
lifetime. The average lifetime values observed were shorter, at approximately 5-6 ns,

477 which is associated with the simple structure of HA. This average lifetime can be 478 attributed to component 1 (Figure 3a) observed in PARAFAC. The average lifetime of component 2, with emission at $530 \mathrm{~nm}$ (Figure 3b) did not appear in the results because the emission spectra in TRF reached only $510 \mathrm{~nm}$ owing to laser leakage at $532 \mathrm{~nm}$.

The best fit for HLA complexes showed a bi-exponential decay $\left(\tau_{1}\right.$ and $\left.\tau_{2}\right)$, the average lifetimes of which were approximately $4 \mathrm{~ns}$ and $14 \mathrm{~ns}$, respectively. These results fit well with the PARAFAC for HLA, which showed two components, one with a simple structure (component 1) and the other with a complex structure (component 2), reflecting lower and higher lifetimes, respectively. The first average lifetime $\tau_{1}$ was almost the same as that for HA (Figure $3 \mathrm{~d}$ ). Lifetime $\tau_{2}$ can be associated with component 2 (Figure 3e), which has a more complex fluorophore structure.

\section{Figure 5}




\section{Conclusion}

HLA were obtained by $\mathrm{NaOH}$ aqueous solution extraction from hydrochar

504

505

\section{Acknowledgments}

This work was supported by the São Paulo Research Foundation (FAPESP) (grants 15/22954-1, 17/26718-6, and 18/15733-7). J.V.S acknowledges a scholarship from FAPESP (grants 17/05408-9 and 18/09914-9). O.P.F acknowledges financial support from FUNCAP (PRONEX PR2-0101-00006.01.00/15). The authors thank Dr. Maurício Boscolo for offering assistance with the FTIR analysis (process 2017/132305) and Dr. Isabella Constatino and Dr. Fabiana Paschoal for their assistance with soil sampling.

\section{References}

Andreazza, R., Okeke, B.C., Lambais, M.R., Bortolon, L., de Melo, G.W.B., de Oliveira 
Camargo, F.A., 2010. Bacterial stimulation of copper phytoaccumulation by bioaugmentation with rhizosphere bacteria. Chemosphere 81, 1149-1154. https://doi.org/10.1016/j.chemosphere.2010.09.047

Bento, L. R.; Melo, C. A.; Ferreira, O. P.; Moreira, A. B.; Mounier, S.; Piccolo, A.; Spaccini, R.; Bisinoti, M.C., 2020. Humic extracts of hydrochar and Amazonian Dark Earth: Molecular characteristics and effects on maize seed germination. Sci. Total Environ. https://doi.org/10.1016/j.scitotenv.2019.135000

Bento, L.R., Melo, C.A., Ferreira, O.P., Moreira, B., Mounier, S., Piccolo, A., Spaccini, R., Bisinoti, M.C., 2019. Humic extracts of hydrochar and Amazonian Dark Earth: Molecular characteristics and effects on maize seed germination. Sci. Total Environ. 135000. https://doi.org/10.1016/j.scitotenv.2019.135000

Budziak, C.R., Maia, C.M.B.F., Mangrich, A.S., 2004. Transformações químicas da matéria orgânica durante a compostagem de resíduos da indústria madeireira. Quim. Nova 27, 399-403. https://doi.org/10.1590/S0100-40422004000300007

Canellas, L.P., Façanha, A.R., 2004. Chemical nature of soil humified fractions and their bioactivity. Pesqui. Agropecu. Bras. 39, 233-240. https://doi.org/10.1590/S0100-204X2004000300005

Chen, J., Chen, H., Zhang, X.W., Lei, K., Kenny, J.E., 2015. Combination of a CopperIon Selective Electrode and Fluorometric Titration for the Determination of Copper(II) Ion Conditional Stability Constants of Humic Substances. Acta radiol. 56, 1293-1302. https://doi.org/10.1366/14-07835

Coble, P.G., 1996. Characterization of marine and terrestrial DOM in the seawater using exciting-emission matrix. Mar. Chem. 51, 325-346. https://doi.org/10.1016/03044203(95)00062-3 
Dick, D. P.; Santos, J. H. Z.; Ferranti, E.M., 2003. Chemical Characterization and Infrared Spectroscopy of Soil Organic Matter From Two Southern Brazilian Soils ( 1 ). Rev. Bras. Cienc. do Solo 27, 29-39. https://doi.org/10.1590/S010006832003000100004

El-Naggar, A., Lee, M.H., Hur, J., Lee, Y.H., Igalavithana, A.D., Shaheen, S.M., Ryu, C., Rinklebe, J., Tsang, D.C.W., Ok, Y.S., 2020. Biochar-induced metal immobilization and soil biogeochemical process: An integrated mechanistic approach. Sci. Total Environ. 698, 134112. https://doi.org/10.1016/j.scitotenv.2019.134112

Elkins, K.M., Nelson, D.J., 2002. Spectroscopic approaches to the study of the interaction of aluminum with humic substances. Coord. Chem. Rev. 228, 205-225. https://doi.org/10.1016/S0010-8545(02)00040-1

Esteves, V.I., Otero, M., Duarte, A.C., 2009. Comparative characterization of humic substances from the open ocean, estuarine water and fresh water. Org. Geochem. 40, 942-950. https://doi.org/10.1016/j.orggeochem.2009.06.006

Fernandes, A.N., Giovanela, M., Esteves, V.I., Sierra, M.M. de S., 2010. Elemental and spectral properties of peat and soil samples and their respective humic substances. J. Mol. Struct. 971, 33-38. https://doi.org/10.1016/j.molstruc.2010.02.069

Francioso, O., Sánchez-Cortés, S., Casarini, D., Garcia-Ramos, J. V., Ciavatta, C., Gessa, C., 2002. Spectroscopic study of humic acids fractionated by means of tangential ultrafiltration. J. Mol. Struct. 609, 137-147. https://doi.org/10.1016/S0022-2860(01)00971-1

Fregolente, L.G., Miguel, T.B.A.R., de Castro Miguel, E., de Almeida Melo, C., Moreira, A.B., Ferreira, O.P., Bisinoti, M.C., 2018. Toxicity evaluation of process 
water from hydrothermal carbonization of sugarcane industry by-products. Environ. Sci. Pollut. Res. 1-11. https://doi.org/10.1007/s11356-018-1771-2

Fu, F., Wang, Q., 2011. Removal of heavy metal ions from wastewaters: A review. J. Environ. Manage. 92, 407-418. https://doi.org/10.1016/j.jenvman.2010.11.011

Fuentes, M., Olaetxea, M., Baigorri, R., Zamarreño, A.M., Etienne, P., Laîné, P., Ourry, A., Yvin, J.C., Garcia-Mina, J.M., 2013. Main binding sites involved in Fe(III) and $\mathrm{Cu}(\mathrm{II})$ complexation in humic-based structures. J. Geochemical Explor. 129, 1417. https://doi.org/10.1016/j.gexplo.2012.12.015

Fukushima, M., Okabe, R., Nishimoto, R., Fukuchi, S., Sato, T., Terashima, M., 2014. Adsorption of pentachlorophenol to a humin-like substance-bentonite complex prepared by polycondensation reactions of humic precursors. Appl. Clay Sci. 87, 136-141. https://doi.org/10.1016/j.clay.2013.10.022

Giovanela, M., Crespo, J.S., Antunes, M., Adamatti, D.S., Fernandes, A.N., Barison, A., Da Silva, C.W.P., Guégan, R., Motelica-Heino, M., Sierra, M.M.D., 2010. Chemical and spectroscopic characterization of humic acids extracted from the bottom sediments of a Brazilian subtropical microbasin. J. Mol. Struct. 981, 111119. https://doi.org/10.1016/j.molstruc.2010.07.038

Glaser, B., Balashov, E., Haumaier, L., Guggenberger, G., Zech, W., 2000. Black carbon in density fractions of anthropogenic soils of the Brazilian Amazon region. Org. Geochem. 31. https://doi.org/10.1016/S0146-6380(00)00044-9

Guo, X., Jiang, J., Xi, B., He, X., Zhang, H., Deng, Y., 2012. Study on the spectral and $\mathrm{Cu}$ (II) binding characteristics of DOM leached from soils and lake sediments in the Hetao region. Environ. Sci. Pollut. Res. 19, 2079-2087. https://doi.org/10.1007/s11356-011-0704-0 
Guo, X. jing, Zhu, N. min, Chen, L., Yuan, D. hai, He, L. sheng, 2015. Characterizing the fluorescent properties and copper complexation of dissolved organic matter in saline-alkali soils using fluorescence excitation-emission matrix and parallel factor analysis. J. Soils Sediments 15, 1473-1482. https://doi.org/10.1007/s11368-015$1113-7$

He, E., Lü, C., He, J., Zhao, B., Wang, J., Zhang, R., Ding, T., 2016. Binding characteristics of $\mathrm{Cu} 2+$ to natural humic acid fractions sequentially extracted from the lake sediments. Environ. Sci. Pollut. Res. 23, 22667-22677. https://doi.org/10.1007/s11356-016-7487-2

Hernández, D., Plaza, C., Senesi, N., Polo, A., 2006. Detection of Copper(II) and zinc(II) binding to humic acids from pig slurry and amended soils by fluorescence spectroscopy. Environ. Pollut. 143, 212-220. https://doi.org/10.1016/j.envpol.2005.11.038

Hladun, K.R., Parker, D.R., Trumble, J.T., 2015. Cadmium, Copper, and Lead Accumulation and Bioconcentration in the Vegetative and Reproductive Organs of Raphanus sativus: Implications for Plant Performance and Pollination. J. Chem. Ecol. 41, 386-395. https://doi.org/10.1007/s10886-015-0569-7

Jindo, K., Sánchez-Monedero, M.A., Matsumoto, K., Sonoki, T., 2019. The efficiency of a low dose of biochar in enhancing the aromaticity of humic-like substance extracted from poultry manure compost. Agronomy 9, 1-10. https://doi.org/10.3390/agronomy9050248

Jindo, K., Sonoki, T., Matsumoto, K., Canellas, L., Roig, A., Sanchez-Monedero, M.A., 2016. Influence of biochar addition on the humic substances of composting manures. Waste Manag. 49, 545-552. 
623

624

625

626

627

628

629

630

631

632

633

634

635

636

637

638

639

640

641

642

643

644

Kabadayi Catalkopru, A., Kantarli, I.C., Yanik, J., 2017. Effects of spent liquor recirculation in hydrothermal carbonization. Bioresour. Technol. 226, 89-93. https://doi.org/10.1016/j.biortech.2016.12.015

Kulikowska, D., Gusiatin, Z.M., Bułkowska, K., Klik, B., 2015. Feasibility of using humic substances from compost to remove heavy metals $(\mathrm{Cd}, \mathrm{Cu}, \mathrm{Ni}, \mathrm{Pb}, \mathrm{Zn})$ from contaminated soil aged for different periods of time. J. Hazard. Mater. 300, 882891. https://doi.org/10.1016/j.jhazmat.2015.08.022

Lakowics, J.R., 1999. Principles of fluorescence spectroscopy, 2nd ed. New York: Kluwer Academic/ Plenum Publisher.

Lesmana, S.O., Febriana, N., Soetaredjo, F.E., Sunarso, J., Ismadji, S., 2009. Studies on potential applications of biomass for the separation of heavy metals from water and wastewater. Biochem. Eng. J. 44, 19-41. https://doi.org/10.1016/j.bej.2008.12.009

Li, Z., Ma, Z., van der Kuijp, T.J., Yuan, Z., Huang, L., 2014. A review of soil heavy metal pollution from mines in China: Pollution and health risk assessment. Sci. Total Environ. 468-469, 843-853. https://doi.org/10.1016/j.scitotenv.2013.08.090

Lu, Y., Allen, H.E., 2002. Characterization of copper complexation with natural dissolved organic matter (DOM) - Link to acidic moieties of DOM and competition by Ca and Mg. Water Res. 36, 5083-5101. https://doi.org/10.1016/S0043-1354(02)00240-3

MacKie, K.A., Müller, T., Kandeler, E., 2012. Remediation of copper in vineyards - A mini review. Environ. Pollut. 167, 16-26. https://doi.org/10.1016/j.envpol.2012.03.023 
Mao, J., Chen, N., Cao, X., 2011. Characterization of humic substances by advanced solid state NMR spectroscopy: Demonstration of a systematic approach. Org. Geochem. 42, 891-902. https://doi.org/10.1016/j.orggeochem.2011.03.023

Matthews, B.J.H., Jones, A.C., Theodorou, N.K., Tudhope, A.W., 1996. Excitationemission-matrix fluorescence spectroscopy applied to humic acid bands in coral reefs. Mar. Chem. 55, 317-332. https://doi.org/10.1016/S0304-4203(96)00039-4

Mazzei, P., Piccolo, A., 2012. Quantitative evaluation of noncovalent interactions between glyphosate and dissolved humic substances by NMR spectroscopy. Environ. Sci. Technol. 46, 5939-5946. https://doi.org/10.1021/es300265a

Melo, C.A., Junior, F.H.S., Bisinoti, M.C., Moreira, A.B., Ferreira, O.P., 2017. Transforming sugarcane bagasse and vinasse wastes into hydrochar in the presence of phosphoric acid: an evaluation of nutrient contents and structural properties. Waste and Biomass Valorization 1139-1151. https://doi.org/10.1007/s12649-0169664-4

Monda, H., Cozzolino, V., Vinci, G., Drosos, M., Savy, D., Piccolo, A., 2018. Molecular composition of the Humeome extracted from different green composts and their biostimulation on early growth of maize. Plant Soil 429, 407-424. https://doi.org/10.1007/s11104-018-3642-5

Monda, H., Cozzolino, V., Vinci, G., Spaccini, R., Piccolo, A., 2017. Molecular characteristics of water-extractable organic matter from different composted biomasses and their effects on seed germination and early growth of maize. Sci. Total Environ. 590-591, 40-49. https://doi.org/10.1016/j.scitotenv.2017.03.026

Mounier, S., Zhao, H., Garnier, C., Redon, R., 2011. Copper complexing properties of dissolved organic matter: PARAFAC treatment of fluorescence quenching. 
670

671

672

673

674

675

676

677

678

679

680

681

682

683

684

685

686

687

688

689

690

691

Mulligan, C.N., 2009. Recent advances in the environmental applications of biosurfactants. Curr. Opin. Colloid Interface Sci. 14, 372-378. https://doi.org/10.1016/j.cocis.2009.06.005

Mulligan, C.N., Yong, R.N., Gibbs, B.F., 2001. Heavy metal removal from sediments by biosurfactants. J. Hazard. Mater. 85, 111-125. https://doi.org/10.1016/S03043894(01)00224-2

Nouhi, A., 2018. Caractérisation Spectrale et Temporelle par Quenching de Fluorescence des Interactions Matière Organique-Eléments Métalliques. Universté de Toulon.

Nouhi, A., Hajjoul, H., Redon, R., Gagné, J.P., Mounier, S., 2018. Time-resolved laser fluorescence spectroscopy of organic ligands by europium: Fluorescence quenching and lifetime properties. Spectrochim. Acta - Part A Mol. Biomol. Spectrosc. 193, 219-225. https://doi.org/10.1016/j.saa.2017.12.028

Oliveira, N.C., Paschoal, A.R., Paula, R.J., Constantino, I.C., Bisinoti, M.C., Moreira, A.B., Fregolente, L.G., Santana, A.M., Sousa, F.A., Ferreira, O.P., Paula, A.J., 2018. Morphological analysis of soil particles at multiple length-scale reveals nutrient stocks of Amazonian Anthrosols. Geoderma 311, 58-66. https://doi.org/10.1016/j.geoderma.2017.09.034

Pearson, R.G., 1963. Hard and Soft Acids and Bases. J. Am. Chem. Soc. 85, 35333539. https://doi.org/10.1021/ja00905a001

Piccolo, A., Spaccini, R., De Martino, A., Scognamiglio, F., di Meo, V., 2019. Soil washing with solutions of humic substances from manure compost removes heavy 

metal contaminants as a function of humic molecular composition. Chemosphere 225, 150-156. https://doi.org/10.1016/j.chemosphere.2019.03.019

Plaza, C., D’Orazio, V., Senesi, N., 2005. Copper(II) complexation of humic acids from the first generation of EUROSOILS by total luminescence spectroscopy. Geoderma 125, 177-186. https://doi.org/10.1016/j.geoderma.2004.07.012

Rajapaksha, A.U., Ok, Y.S., El-Naggar, A., Kim, H., Song, F., Kang, S., Tsang, Y.F., 2019. Dissolved organic matter characterization of biochars produced from different feedstock materials. J. Environ. Manage. 233, 393-399. https://doi.org/10.1016/j.jenvman.2018.12.069

Ryan, D.K., Weber, J.H., 1982. Fluorescence Quenching Titration for Determination of Complexing Capacities and Stability Constants of Fulvic Acid. Anal. Chem. 54, 986-990. https://doi.org/10.1021/ac00243a033

Senesi, N., D’Orazio, V., Ricca, G., 2003. Humic acids in the first generation of EUROSOILS. Geoderma 116, 325-344. https://doi.org/10.1016/S00167061(03)00107-1

Silva, C.C., Melo, C.A., Soares Junior, F.H., Moreira, A.B., Ferreira, O.P., Bisinoti, M.C., 2017. Effect of the reaction medium on the immobilization of nutrients in hydrochars obtained using sugarcane industry residues. Bioresour. Technol. 237, 213-221. https://doi.org/10.1016/j.biortech.2017.04.004

Spaccini, R., Cozzolino, V., Di Meo, V., Savy, D., Drosos, M., Piccolo, A., 2019. Bioactivity of humic substances and water extracts from compost made by lignocellulose wastes from biorefinery. Sci. Total Environ. 646, 792-800. https://doi.org/10.1016/j.scitotenv.2018.07.334 
Spaccini, R., Piccolo, A., 2009. Molecular characteristics of humic acids extracted from compost at increasing maturity stages. Soil Biol. Biochem. 41, 1164-1172. https://doi.org/10.1016/j.soilbio.2009.02.026

Stedmon, C.A., Bro, R., 2008. Characterizing dissolved organic matter fluorescence with parallel factor analysis: a tutorial. Limnol. Oceanogr. 6, 1-8. https://doi.org/10.4319/lom.2008.6.572

Stedmon, C.A., Markager, S., Bro, R., 2003. Tracing dissolved organic matter in aquatic environments using a new approach to fluorescence spectroscopy. Mar. Chem. 82, 239-254. https://doi.org/10.1016/S0304-4203(03)00072-0

Stemann, J., Putschew, A., Ziegler, F., 2013. Hydrothermal carbonization: Process water characterization and effects of water recirculation. Bioresour. Technol. 143, 139-146. https://doi.org/10.1016/j.biortech.2013.05.098

Stevenson, F.J., 1994. Humus chemistry: Genesis, composition, and reactions. New York John Wiley Sons.

Swift, R.S., 1996. Methods of soil analysis. Part 3. Chemical methods. Soil Sci. Soc. Am. 1011-1020.

Tadini, A. M.; Mounier, S.; Milori, D.M.B.P., 2019. Modeling the quenching of fluorescence from organic matter in Amazonian soils. Sci. Total Environ. 698, 134067. https://doi.org/10.1016/j.scitotenv.2019.134067

Tadini, A.M., Constantino, I.C., Nuzzo, A., Spaccini, R., Piccolo, A., Moreira, A.B., Bisinoti, M.C., 2015. Characterization of typical aquatic humic substances in areas of sugarcane cultivation in Brazil using tetramethylammonium hydroxide thermochemolysis. Sci. Total Environ. 518-519, 201-208. 
Tang, W.W., Zeng, G.M., Gong, J.L., Liang, J., Xu, P., Zhang, C., Huang, B. Bin, 2014. Impact of humic/fulvic acid on the removal of heavy metals from aqueous solutions using nanomaterials: A review. Sci. Total Environ. 468-469, 1014-1027. https://doi.org/10.1016/j.scitotenv.2013.09.044

US EPA, 2000. Environmental Protection Agency, Environmental Response Team. Standard operating procedures - SOP 1-4.

Uyguner, C.S., Bekbolet, M., 2005. Evaluation of humic acid photocatalytic degradation by UV-vis and fluorescence spectroscopy. Catal. Today 101, 267-274. https://doi.org/10.1016/j.cattod.2005.03.011

Weiner, B., Poerschmann, J., Wedwitschka, H., Koehler, R., Kopinke, F.D., 2014. Influence of Process Water Reuse on Hydrothermal Carbonization of Paper. Sustain. Chem. Eng. 2, 2165-2171. https://doi.org/10.1021/sc500348v

Yang, F., Zhang, S., Cheng, K., Antonietti, M., 2019. A hydrothermal process to turn waste biomass into artificial fulvic and humic acids for soil remediation. Sci. Total Environ. 686, 1140-1151. https://doi.org/10.1016/j.scitotenv.2019.06.045

Yang, X., Tsibart, A., Nam, H., Hur, J., El-Naggar, A., Tack, F.M.G., Wang, C.H., Lee, Y.H., Tsang, D.C.W., Ok, Y.S., 2019. Effect of gasification biochar application on soil quality: Trace metal behavior, microbial community, and soil dissolved organic matter. J. Hazard. Mater. 365, 684-694. https://doi.org/10.1016/j.jhazmat.2018.11.042

Yuan, D.H., Guo, X.J., Wen, L., He, L.S., Wang, J.G., Li, J.Q., 2015. Detection of Copper (II) and Cadmium (II) binding to dissolved organic matter from 

macrophyte decomposition by fluorescence excitation-emission matrix spectra combined with parallel factor analysis. Environ. Pollut. 204, 152-160.

763 https://doi.org/10.1016/j.envpol.2015.04.030

764

765

766

767

768

769

770

Zherebtsov, S.I., Malyshenko, N. V., Bryukhovetskaya, L. V., Lyrshchikov, S.Y., Ismagilov, Z.R., 2015. Sorption of copper cations from aqueous solutions by brown coals and humic acids. Solid Fuel Chem. 49, 294-303. https://doi.org/10.3103/S0361521915050110 
Table 1. Biomass, additives, temperature, and reaction time used for hydrothermal carbonization and recarbonization.

\begin{tabular}{|c|c|c|c|c|c|}
\hline $\begin{array}{l}\text { Carbonization/ } \\
\text { Recarbonization }\end{array}$ & Reaction & Biomass & $\begin{array}{l}\text { Additive } \\
(4 \% \mathrm{v} / \mathrm{v})\end{array}$ & Temp. & Time \\
\hline $\mathbf{H H}_{3} \mathbf{P O}_{4}$ & 1 & $\begin{array}{l}\text { Vinasse } \\
\text { Sugarcane } \\
\text { bagasse }\end{array}$ & $\begin{array}{c}\text { Phosphoric } \\
\text { Acid }\end{array}$ & $230{ }^{\circ} \mathrm{C}$ & $13 \mathrm{~h}$ \\
\hline $\mathbf{H H}_{2} \mathbf{S O}_{4}$ & 2 & $\begin{array}{c}\text { Vinasse } \\
\text { Sugarcane } \\
\text { bagasse }\end{array}$ & $\begin{array}{l}\text { Sulfuric } \\
\text { Acid }\end{array}$ & $230{ }^{\circ} \mathrm{C}$ & $13 \mathrm{~h}$ \\
\hline $\mathbf{R H H}_{3} \mathbf{P O}_{4}$ & 3 & $\begin{array}{c}\text { Process water } \\
\text { (from reaction1) } \\
\text { Sugarcane } \\
\text { bagasse }\end{array}$ & $\begin{array}{c}\text { Phosphoric } \\
\text { Acid }\end{array}$ & $230{ }^{\circ} \mathrm{C}$ & $13 \mathrm{~h}$ \\
\hline $\mathbf{R H H}_{2} \mathbf{S O}_{4}$ & 4 & $\begin{array}{c}\text { Process water } \\
\text { (from reaction 2) } \\
\text { Sugarcane } \\
\text { bagasse }\end{array}$ & $\begin{array}{l}\text { Sulfuric } \\
\text { Acid }\end{array}$ & $230{ }^{\circ} \mathrm{C}$ & $13 \mathrm{~h}$ \\
\hline
\end{tabular}


Table 2. Carbon $(\mathrm{C})$, hydrogen $(\mathrm{H})$, nitrogen $(\mathrm{N})$, oxygen $(\mathrm{O})$ and sulfur $(\mathrm{S})$ contents; O/C, H/C, and $\mathrm{C} / \mathrm{N}$ atomic ratios; and absorbance ratios $\mathrm{E}_{465} / \mathrm{E}_{665}$ and $\mathrm{E}_{270} / \mathrm{E}_{407}$ for HA and HLA samples.

\begin{tabular}{|c|c|c|c|c|c|c|c|c|c|c|}
\hline HA/HLA & $\begin{array}{c}C \\
(\%)\end{array}$ & $\underset{(\%)}{\mathbf{H}}$ & $\begin{array}{c}\mathbf{N} \\
(\%)\end{array}$ & $\begin{array}{c}\mathbf{O} \\
(\%)\end{array}$ & $\begin{array}{c}\mathbf{S} \\
(\%)\end{array}$ & $\mathrm{O} / \mathrm{C}$ & H/C & $\mathbf{C} / \mathbf{N}$ & $\mathbf{E}_{465} / \mathbf{E}_{665}$ & $\mathbf{E}_{270} / \mathbf{E}_{\mathbf{4 0 7}}$ \\
\hline TM I* & 51.24 & 3.80 & 3.41 & 40.61 & 0.94 & 0.59 & 0.89 & 17.80 & 3.92 & 2.81 \\
\hline TM II* & 39.62 & 4.05 & 4.04 & 51.37 & 0.92 & 0.97 & 1.23 & 11.38 & 4.33 & 3.43 \\
\hline TM III* & 50.22 & 3.69 & 2.97 & 42.14 & 0.98 & 0.63 & 0.88 & 19.95 & 4.18 & 2.90 \\
\hline $\mathrm{HH}_{2} \mathrm{SO}_{4 * *}$ & 51.95 & 5.25 & 1.47 & 39.88 & 1.45 & 0.57 & 1.21 & 43.30 & 5.71 & 4.06 \\
\hline $\mathrm{HH}_{3} \mathrm{PO}_{4}{ }^{* *}$ & 62.27 & 5.62 & 2.60 & 28.47 & 1.04 & 0.34 & 1.08 & 28.83 & 5.33 & 3.93 \\
\hline $\mathrm{RHH}_{2} \mathrm{SO}_{4 * *}$ & 48.90 & 4.46 & 1.20 & 37.99 & 7.45 & 0.58 & 1.09 & 51.00 & 3.50 & 3.33 \\
\hline $\mathrm{RHH}_{3} \mathrm{PO}_{4} * *$ & 53.54 & 4.82 & 1.83 & 35.92 & 0.89 & 0.50 & 1.08 & 34.31 & 4.67 & 3.19 \\
\hline
\end{tabular}

* natural humic acids; ** humic-like acids 
Table 3. Relative value (\% of total area) and indexes obtained from ${ }^{13} \mathrm{C}-\mathrm{CPMAS}$ - NMR spectra of HA and HLA samples.

\begin{tabular}{|c|c|c|c|c|c|c|c|c|c|c|}
\hline \multirow[b]{2}{*}{ HA/HLA } & \multicolumn{7}{|c|}{${ }^{13} \mathrm{C}$ NMR region (ppm) } & \multicolumn{3}{|c|}{${ }^{13}$ C NMR indexes } \\
\hline & $220-190$ & $190-160$ & $160-145$ & $145-110$ & $110-60$ & $60-45$ & 45-0 & ARM & $\mathrm{A} / \mathrm{OA}$ & HB/HI \\
\hline TM I* & 4.93 & 15.41 & 5.86 & 34.98 & 17.87 & 5.55 & 15.41 & 1.23 & 0.86 & 1.45 \\
\hline TM II $^{\#}$ & - & - & - & - & - & - & - & - & - & - \\
\hline TM III* & 6.43 & 14.11 & 4.98 & 30.08 & 17.22 & 6.43 & 20.75 & 0.92 & 1.20 & 1.48 \\
\hline $\mathrm{HH}_{2} \mathrm{SO}_{4}{ }^{* *}$ & 1.75 & 6.11 & 6.55 & 33.62 & 3.06 & 5.24 & 43.67 & 0.86 & 14.29 & 5.19 \\
\hline $\mathrm{HH}_{3} \mathrm{PO}_{4}{ }^{* *}$ & 2.55 & 2.55 & 3.57 & 29.59 & 1.02 & 9.69 & 51.02 & 0.64 & 50.00 & 5.32 \\
\hline $\mathbf{R H H}_{2} \mathrm{SO}_{4} * *$ & 3.03 & 5.30 & 7.95 & 42.80 & 2.65 & 0.38 & 37.88 & 1.25 & 14.29 & 7.80 \\
\hline $\mathbf{R H H}_{3} \mathbf{P O}_{4} * *$ & 1.79 & 1.79 & 8.04 & 36.16 & 0.45 & 7.14 & 44.64 & 0.98 & 100.00 & 7.96 \\
\hline
\end{tabular}

* natural humic acids; ** humic-like acids; ${ }^{\#}$ not realized / ARM = aromaticity index [(110 - 160) / $\left.\Sigma(0-45)+(60-110)\right] ; \mathrm{A} / \mathrm{OA}=$ alkyl/O-alkyl index $(0-45) /(60-$ $110) ; \mathrm{HB} / \mathrm{HI}=$ hydrophobicity index $=[\Sigma(0-45)+(110-160) / \Sigma(45-60)+(60-110)+(160-190)]$. 
Table 4. $\log \mathrm{K}, \mathrm{CL}, \mathrm{CC}$, and bias values for components 1 and 2 regarding the interaction of HA and HLA with Cu(II) ions.

\begin{tabular}{|c|c|c|c|c|c|c|c|c|}
\hline \multirow{2}{*}{ HA/HLA } & \multicolumn{4}{|c|}{ Component 1} & \multicolumn{4}{|c|}{ Component 2} \\
\hline & Bias & $\begin{array}{c}\mathrm{CL} \\
\left(\mathrm{mol} \mathrm{L}^{-1}\right)\end{array}$ & $\log K$ & $\begin{array}{c}\mathrm{CC} \\
\left(\mathrm{mmol}^{-1} \mathrm{Cu}\right. \\
\left.\mathrm{g}^{-1} \mathrm{C}\right)\end{array}$ & Bias & $\begin{array}{c}\text { CL } \\
\left(\mathrm{mol} \mathrm{L}^{-1}\right)\end{array}$ & $\log K$ & $\begin{array}{c}\mathrm{CC} \\
\left(\mathrm{mmol}^{-1} \mathrm{Cu}\right. \\
\left.\mathrm{g}^{-1} \mathrm{C}\right)\end{array}$ \\
\hline TM I* & 2.25 & $6.50 \mathrm{E}-06$ & 5.36 & 1.27 & 4.18 & $3.50 \mathrm{E}-06$ & 5.58 & 0.68 \\
\hline TM II* & 0.96 & $6.70 \mathrm{E}-06$ & 5.41 & 1.69 & 2.18 & $3.20 \mathrm{E}-06$ & 5.60 & 0.81 \\
\hline TM III* & 1.98 & $8.00 \mathrm{E}-06$ & 5.30 & 1.59 & 2.29 & $4.50 \mathrm{E}-06$ & 5.59 & 0.90 \\
\hline $\mathrm{HH}_{2} \mathrm{SO}_{4} * *$ & 2.04 & $2.40 \mathrm{E}-05$ & 4.89 & 4.62 & 2.67 & $1.00 \mathrm{E}-05$ & 5.09 & 1.92 \\
\hline $\mathrm{HH}_{3} \mathrm{PO}_{4} * *$ & 0.47 & $2.40 \mathrm{E}-05$ & 4.88 & 3.85 & 0.49 & $1.70 \mathrm{E}-05$ & 5.06 & 2.73 \\
\hline $\mathbf{R H H}_{2} \mathbf{S O}_{4} * *$ & 0.71 & $3.20 \mathrm{E}-05$ & 4.89 & 6.54 & 0.77 & $2.50 \mathrm{E}-05$ & 5.08 & 5.11 \\
\hline $\mathbf{R H H}_{3} \mathbf{P O}_{4} * *$ & 0.27 & $1.80 \mathrm{E}-05$ & 4.90 & 3.36 & 0.35 & $1.40 \mathrm{E}-05$ & 5.09 & 2.61 \\
\hline
\end{tabular}

* natural humic acids; ** humic-like acids 


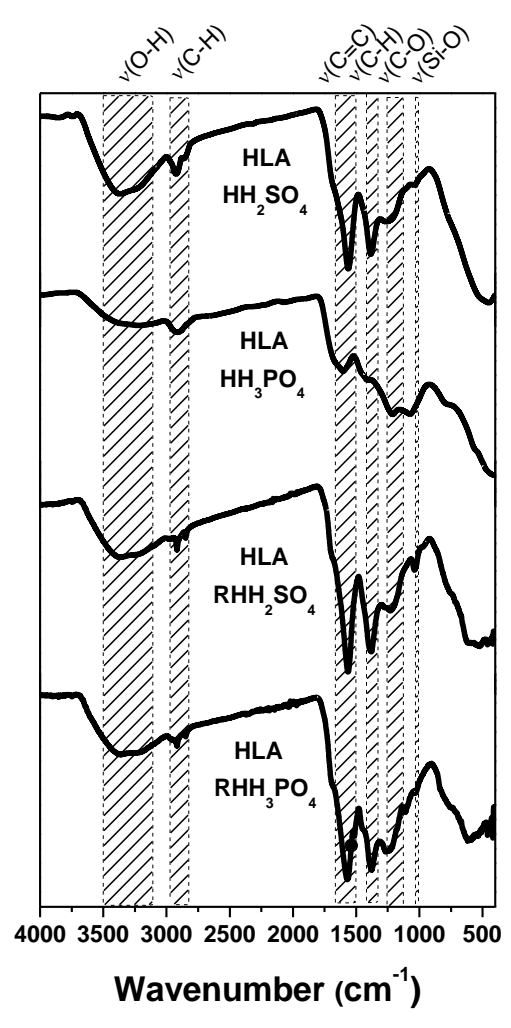

(a)

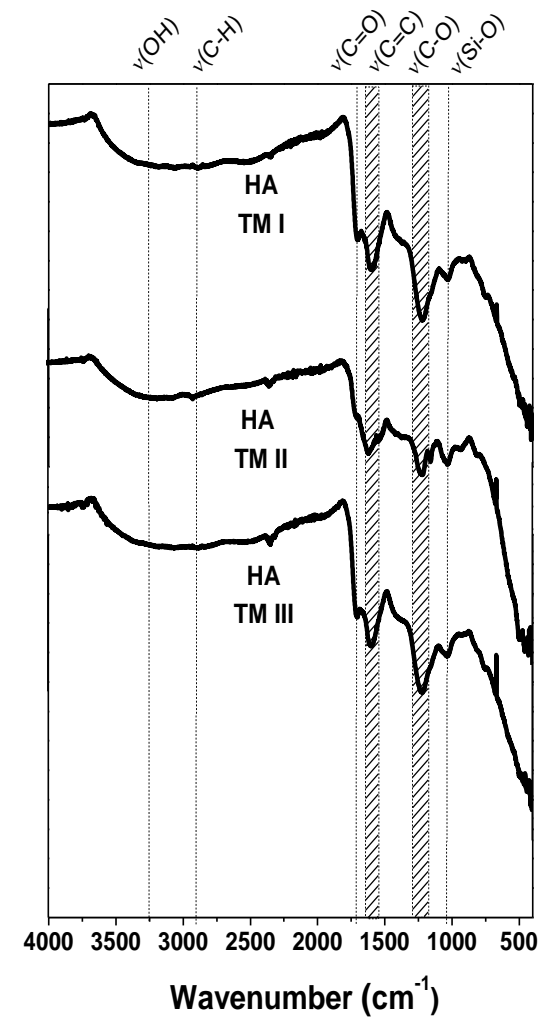

(b)

Fig.1. FTIR spectra for HLA isolated from hydrochar (a) and HA isolated from soil (b). 


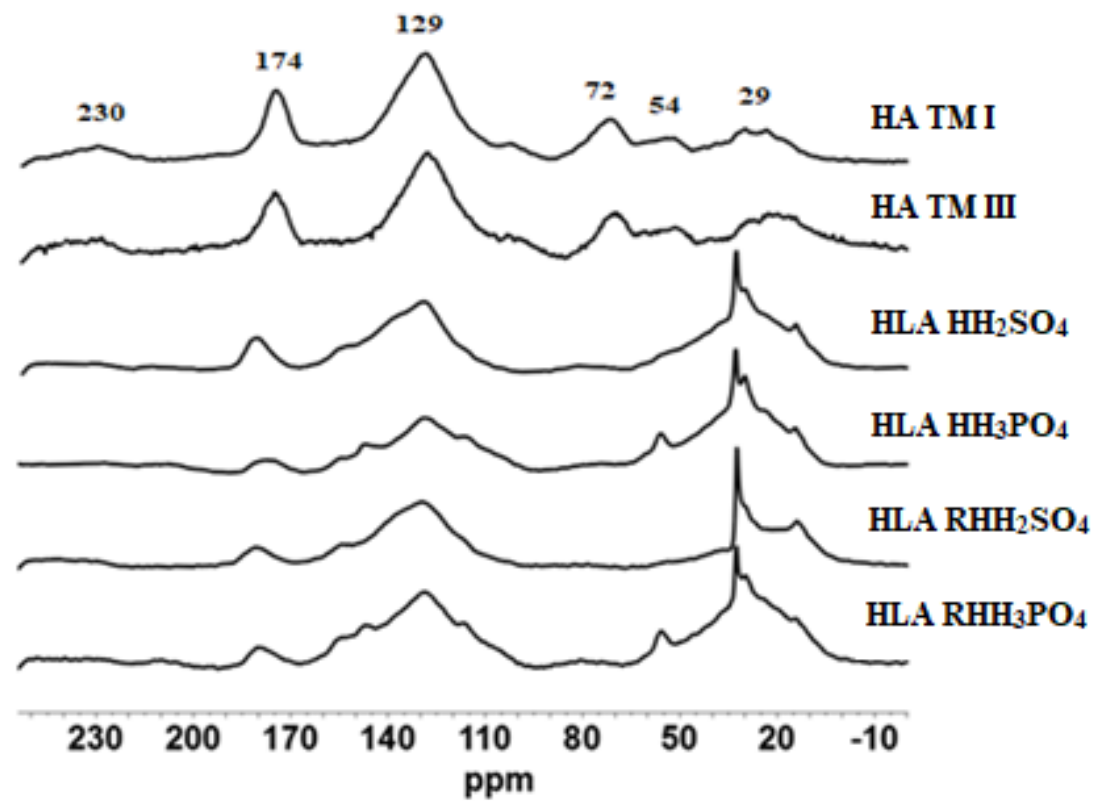

Fig.2. Solid-state ${ }^{13} \mathrm{C}$ NMR spectra of HA and HLA. 


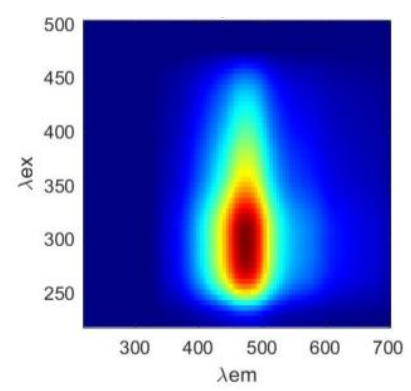

(a)

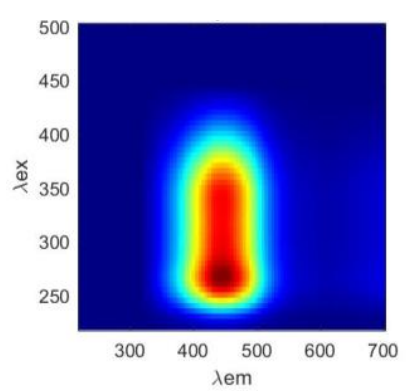

(d)

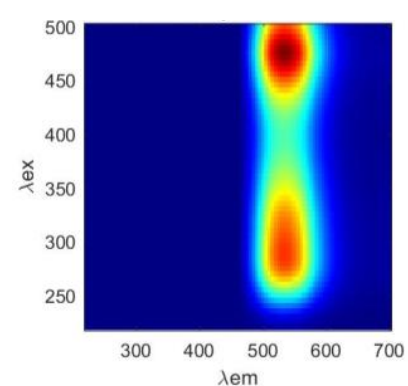

(b)

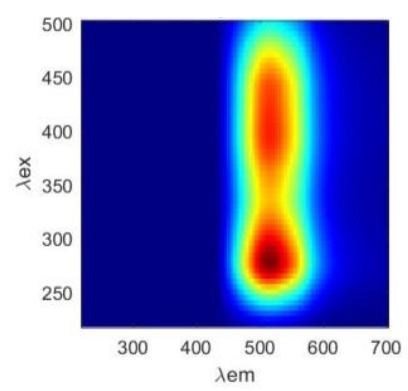

(e)

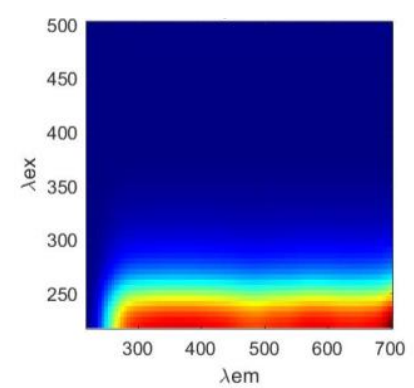

(c)

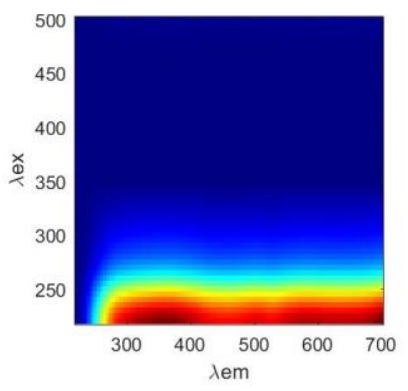

(f)

Fig. 3. Components 1, 2, and 3 obtained by CP/PARAFAC for interaction of HA (a, b and c, respectively) and components 1, 2, and 3 for interaction of HLA (d, e and f, respectively) with $\mathrm{Cu}(\mathrm{II})$ ions. 


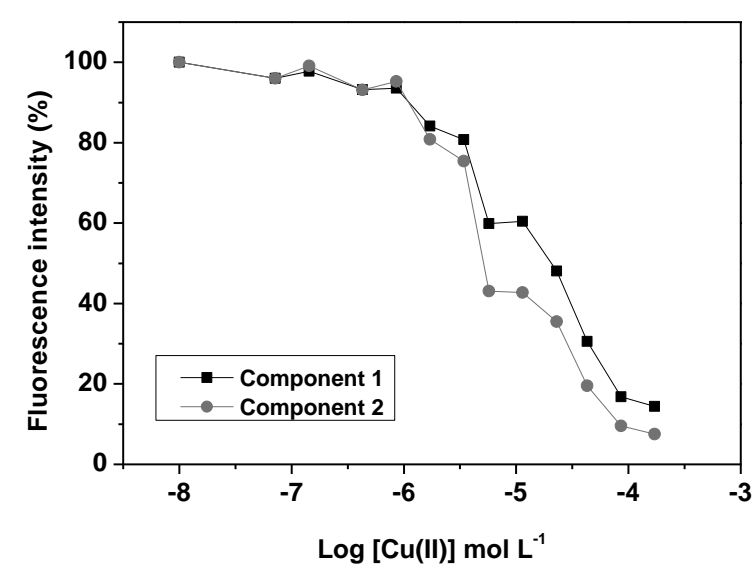

(a)

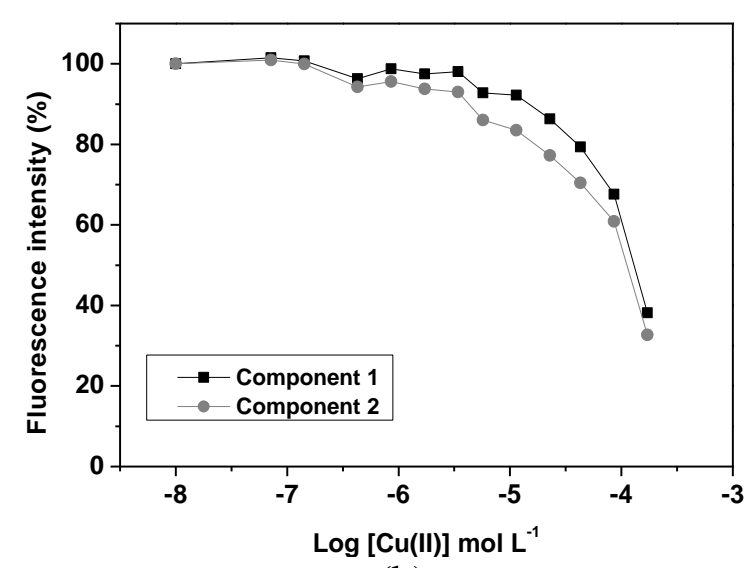

(b)

Fig. 4. Contribution of relative fluorescence intensity for components 1 and 2 regarding the interaction of TM I HA (a) and $\mathrm{HH}_{2} \mathrm{SO}_{4} \mathrm{HLA}$ (b) with $\mathrm{Cu}$ (II) ions. 


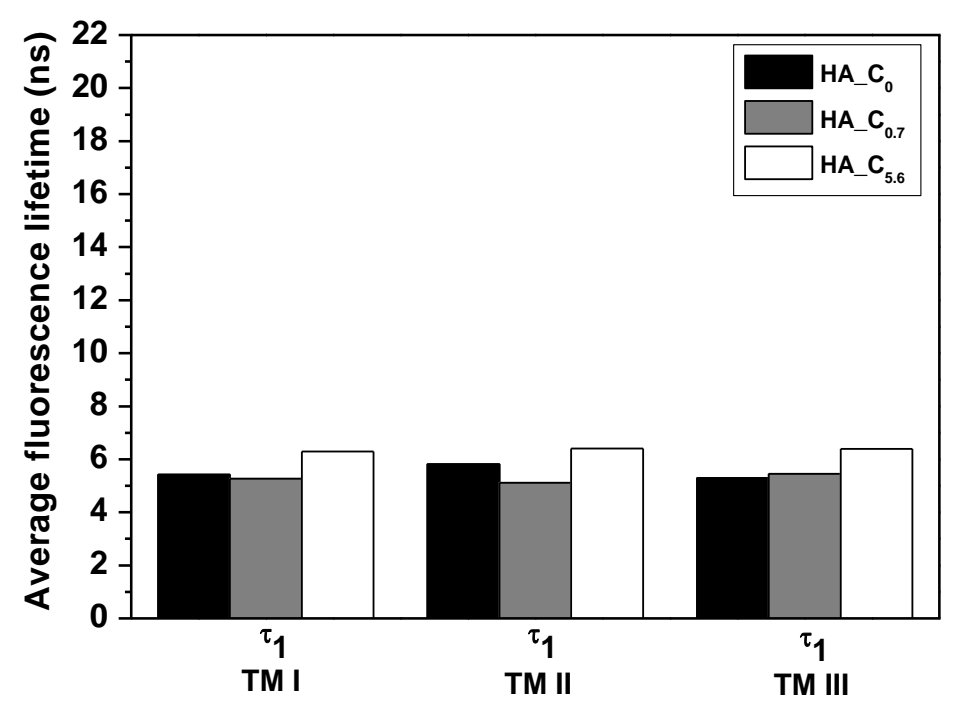

(a)

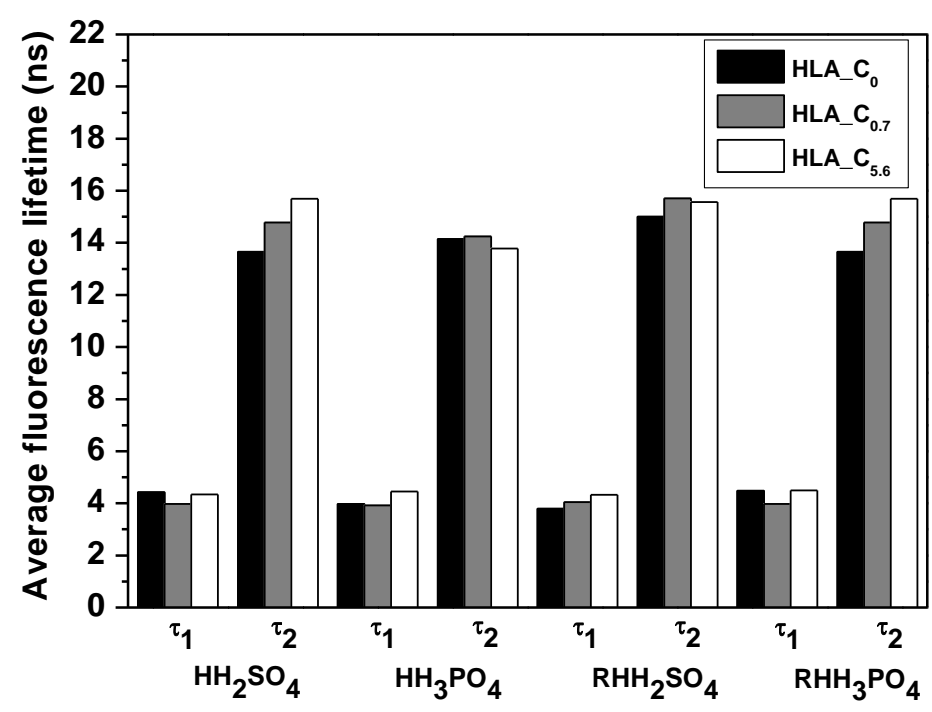

(b)

Fig. 5. Average fluorescence lifetime distribution for HA $\left(\tau_{1}\right)$ (a) and HLA ( $\tau_{1}$ and $\left.\tau_{2}\right)$ (b) when interacting with $\mathrm{Cu}(\mathrm{II})$ ions at concentration: $\mathrm{C}_{0}=$ no copper added, $\mathrm{C}_{0.7}=0.7 \mathrm{mg} \mathrm{L}^{-1}$ and $\mathrm{C}_{5.6}=5.6 \mathrm{mg} \mathrm{L}^{-1}$. 